\title{
The separation mechanism and application of a tapered diameter separation bed
}

\author{
Y. M. Zhao - C. L. Duan - L. L. Wu • \\ H. J. Zhang $\cdot$ J. F. He $\cdot$ Y. Q. He
}

Received: 26 May 2011/Revised: 8 October 2011/Accepted: 12 January 2012/Published online: 2 August 2012

(c) CEERS, IAU 2012

\begin{abstract}
Research on recycling waste printed circuit boards is at the forefront of preventing environmental pollution and finding ways to recycle resources. A wet process for reclaiming metals from printed circuit boards applying a tapered diameter separation bed is described, and the separation mechanism of the device is proposed. The motion of a particle in the tapered diameter fluid flow field and particle separation within this field were studied. As the material passes through the fluid field, along with the water, differences in particle density, granularity, and shape cause particles to follow at different trajectories. A tapered diameter separation bed was used to process 1-0.074 mm-sized crushed material from discarded printed circuit boards. The separation efficiency of $91.77 \%$ and the recovery rate of $95.79 \%$ for recovered metal were achieved with a discharge water flow rate of $4.5 \mathrm{~m}^{3} / \mathrm{h}$, a material feed rate of $300 \mathrm{~g} / \mathrm{min}$, and an obliquity of $30^{\circ}$. For $-0.074 \mathrm{~mm}$ printed circuit boards, the metal recovery is $93.42 \%$ and the separation efficiency is $77.63 \%$ when the water discharge is $2 \mathrm{~m}^{3} / \mathrm{h}$, the obliquity is $35^{\circ}$, and the material feed rate is $450 \mathrm{~g} / \mathrm{min}$. The superfine products in a size range of $-0.074 \mathrm{~mm}$ can be recovered effectively under suitable operating condition using the tapered diameter separation bed. It indicates that the lower separation limit of the tapered diameter separation bed can be close to zero. The technique will prevent environmental
\end{abstract}

Y. M. Zhao · C. L. Duan ( $)$ - L. L. Wu · H. J. Zhang

School of Chemical Engineering and Technology,

China University of Mining and Technology,

Xuzhou 221008, Jiangsu, China

e-mail: clduan@cumt.edu.cn

Y. M. Zhao · H. J. Zhang - J. F. He · Y. Q. He

Key Laboratory of Coal Processing and Efficient Utilization, Ministry of Education, Xuzhou 221008, Jiangsu, China pollution from waste printed circuit boards and allow efficient recovery.

Keywords Electronic recycling - Dynamics model · Separator · Waste printed circuit boards

\section{Introduction}

The rapid development of the electronics industry has increased the demand for printed circuit boards (PCB). PCB is widely applied in the fields of information, communication, consumer electronics, military, spaceflight, and so on. Consequently, a large amount of waste PCB material is generated. This waste has a high potential value because it contains 20 kinds of non-ferrous and rare metals. The typical metals in PCB consist of copper (20\%), iron (8\%), tin (4\%), nickel (2\%), lead (2\%), zinc (1\%), silver $(0.2 \%)$, gold $(0.1 \%)$, and palladium (0.005 \%).It may be called a 'gold mine' waiting to be exploited (Owens et al. 2007; Guo et al. 2009; Huang et al. 2009). The metallic grade of waste printed circuit boards is the equivalent of several, to hundreds of, times the metallic grade found in common minerals (Kara 2011; Zhao et al. 2009; He and Zhao 2009). One ton of printed circuit boards contains $80-1,500 \mathrm{~g}$ of gold and $160-210 \mathrm{~kg}$ of copper, which is equivalent to 40-800 times the gold grade and 30-40 times the copper grade found in the USA ( $\mathrm{Li}$ et al. 2007a, b; Duan et al. 2009). Waste PCB material also contains a number of heavy metals including lead, cadmium, mercury, and nickel as well as brominated flame retardants, all of which present a potential danger to the soil, the environment, and to biological organisms (Chien and Shih 2007; Cui and Forssberg 2003). Huge profits have encouraged widespread extraction of metals from waste printed circuit boards by the simple 
methods of acid leaching or furnace cupola burning. But, these methods may cause more serious ecological damage. The recycling of waste PCB also is a focus topic in the field of environment protection and resource recycling (Zhou and Qiu 2010; Wu et al. 2009; Das et al. 2009).

Hydrometallurgy processes have been used to recycle precious metals with higher grade and recovery, such as gold, silver and non-ferrous metals of copper and zinc, but the residual of leaching and wasted water may readily cause more fearful second pollution (Lee et al. 2007; Kim et al. 2011; Oishi et al. 2007; Park and Fray 2009; Mohiuddin et al. 2010). Pyrometallurgy is another traditional technology for recycling non-ferrous metals, ferrous metals as well as precious metals from waste PCB, which mainly includes incineration, smelting in a plasma arc furnace or blast furnace, drossing, sintering, melting, and reactions in a gas phase at high temperatures. However, the large-scale recovery of metals from waste PCB by pyrometallurgy is highly dependent on equipment investments and waste air processing (Cui and Zhang 2008; He et al. 2006; Huang et al. 2009; Tippayawong and Khongkrapan 2009). Pyrolysis of organic materials contained in waste PCBs leads to the formation of gases and oils, which can be used as fuels (Long et al. 2010; Li et al. 2010; Guan et al. 2008). However, the absence of oxygen in the heating process causes the formation of char and gives the solid product low value (Zheng et al. 2009).

In recent years, the mechanical recycling process has drawn more attention due to its better environmental property, high efficiency, and easier operability; additionally, non-ferrous metal and precious metal contents have gradually decreased in concentration in PCBs (Zhao et al. 2004; Li et al. 2008; He et al. 2011). Mechanical recycling process for waste PCBs is based on the differences of materials in physical characteristics including density, magnetic susceptibilities, electric conductivity, etc. ( $\mathrm{Li}$ et al. 2007a, b; Lu et al. 2008; Duan et al. 2009). This concentrate can then be handled using chemical methods to achieve further separation and purification (Veit et al. 2006). The main components of the non-metallic concentrate are resin and glass fibers, which usually can be used as fillers, waterproofing materials, or building materials to realize some utility from them. The main problems of the mechanical process is the low separation efficiency for the fine particles $(-0.074 \mathrm{~mm})$.

Hence, it is extremely urgent to develop a treatment of waste printed circuit boards that is highly efficient and clean. The metal has more than $90 \%$ liberation degree when the particle size of the broken waste PCB is smaller than $1 \mathrm{~mm}$ (Duan et al. 2009). The large density difference between metal and non-metal was used in the design of a tapered column separation bed intended to recycle crushed PCB material sized smaller than $1 \mathrm{~mm}$. The separation mechanism of the tapered column bed and the motion of the particles within the bed will be discussed. The separation principle of the equipment (by density) is revealed. A multi-factor separation experiment was designed using waste PCB having a particle size range from 1 to $0.074 \mathrm{~mm}$ using Design-Expert software. The influence on separation of the discharge water, the feed rate of the material, and the obliquity were studied and the operating conditions for separation were optimized. There is little material in the waste PCB smaller than $0.074 \mathrm{~mm}$ and the metal content of this material is very low, so an orthogonal experiment was carried when studying the recovery of metallic particles $-0.074 \mathrm{~mm}$ in the waste PCB material. The separation results indicate the superfine products in a size range of $-0.074 \mathrm{~mm}$ can be recovered effectively under suitable operating condition using the tapered diameter separation bed. It indicates that the lower separation limit of particle size to the tapered diameter separation bed (TDSB) can be close to zero. The technique will prevent environmental pollution from waste PCB and allow the efficiency recovery of resources. The whole research was carried out in the mineral processing center of China University of Mining and Technology during the period of March 2006 until now.

\section{Materials and methods}

The design of the tapered column separation bed

A new style separator TDSB using water as the medium was designed based on computational fluid dynamic calculations and the theory of inclined flow separation (Zhao et al. 2008). It was designed specifically to recycle metals from waste PCB material. An organic glass was used as the material of construction so that the separation process could be observed. The laboratory scale TDSB had a top diameter of $200 \mathrm{~mm}$, a bottom diameter of $120 \mathrm{~mm}$, and a height of $800 \mathrm{~mm}$. This design was chosen as appropriate for the density, particle size, and hydraulic conditions required obtaining secondary metal concentrate from waste. Improved homogeneity and stability of the fluid were obtained by designing a distributor, as shown in Fig. 1. The perforation pattern of the distributor is asymmetric and the perforation density increases from the center to the edge of the distributor. The design depends primarily on the following points: (1) it helps to produce a stable, rising fluid and improves the asymmetric distribution of flow velocity across the section; (2) the aperture, style, and perforation distribution of the distributor are chosen after considering the particle size difference, the separation of metals and non-metals, and the concentrating and discharging of different sized products; (3) it is easier to manufacture and prevents hole choking of the distributor. 


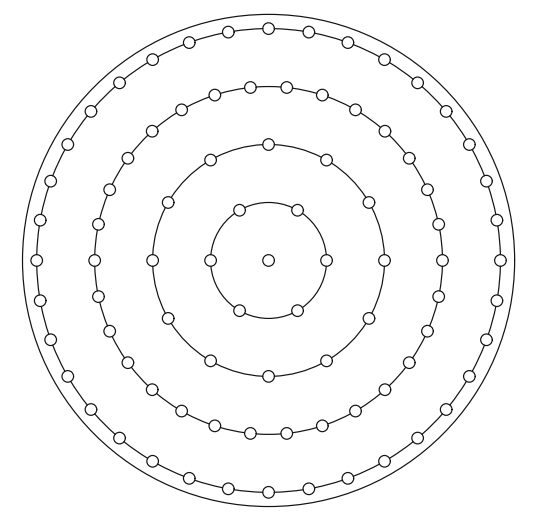

Fig. 1 Sketch map of holes distribution of distributor

A pump circulates water from a tank into the bottom of the TDSB: the water supply is easily adjusted. A mixture of slime, which has been homogenized in a beater, enters the upper part of the TDSB after a dynamic equilibrium of the flow field is established. The amount of material supplied can be controlled according to the capacity of the TDSB. The material freely diffuses due to the action of the hydraulic conditions within the TDSB. Lighter material refluxes into the circulation water tank with the flowing water where it is separated by a filter. The water was recycled after a physical precipitation. Heavier materials are extracted from a different discharge outlet according to the hydraulic conditions. The laboratory design used separation of an inclined fluid to widen the scale of separation size. The TDSB system is shown in Fig. 2.

The core separation equipment was designed especially for separating crushed waste PCB material of multiple densities. The principle of a two-phase fluid was used. Laminar and turbulent flows can coexist within the tapered column: Turbulent flow increases mixing of the materials with water, which is favorable for the particle separation given different material compositions. Laminar flow provides an orderly settlement environment. Separation of metallic from non-metallic particles is ensured because the characteristic motion of these particles differs because of the machine parameters. The separation body is tilted to increase the velocity gradient of the rising water and to broaden the minimum limit of separation.

Separation theory of varied motion of the equal settling particles. Particles which had different density, different size and equal terminal velocity in free settling were called equal settling particles. When the particles possessed the same terminal velocity of particle settling, there were varied motions before coming to the terminal velocity.

Particles moved under the effect of gravity $(G)$, floatage $(F)$, and medium resistance $(R)$ in the free settling process. The relation between composition of forces and movement acceleration is as follows:

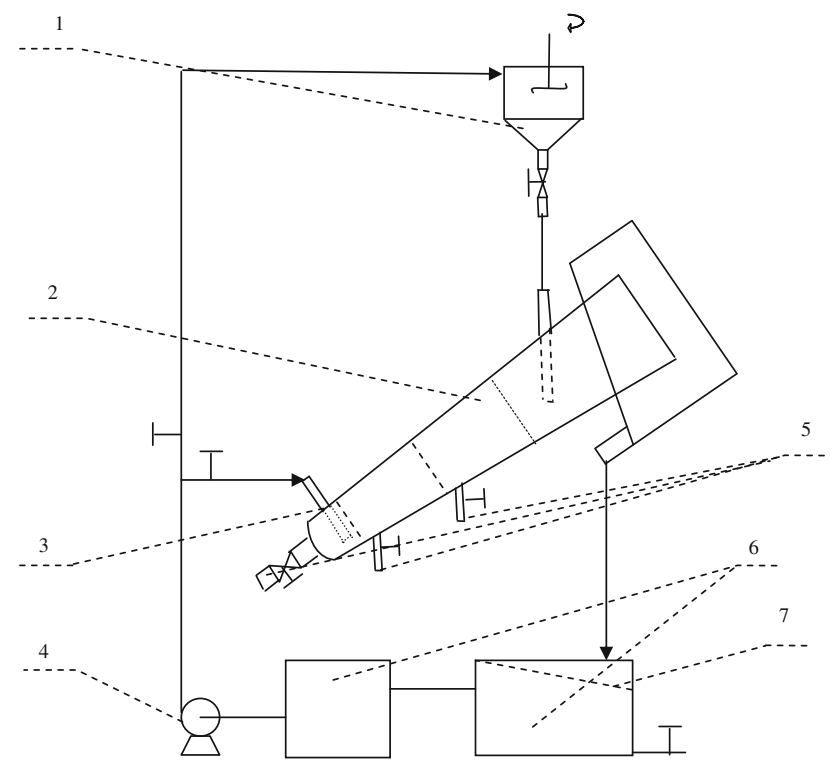

Fig. 2 The water medium-varied diameter separation bed system. 1 Beater, 2 separation bed, 3 distributor, 4 water pump, 5 discharge outlet, 6 circulation water tank, 7 filter cloth

$G-F-R=m \frac{\mathrm{d} v}{\mathrm{~d} t}$

$G=m g=\rho_{\mathrm{s}} g V$

$F=\rho g V$

$R=\psi d^{2} v^{2} \rho$

On the assumption that particles were spherical, $G, F$, and $R$ were substituted into the equation:

$\frac{\mathrm{d} v}{\mathrm{~d} t}=\frac{\rho_{\mathrm{s}}-\rho}{\rho_{\mathrm{s}}} g-\frac{6 \psi v^{2} \rho}{\pi d \rho_{\mathrm{s}}}$

where $V$ is the volume of spherical particles, $\mathrm{m}^{3} ; m$ is the quality of the spherical particles, $\mathrm{k}_{\mathrm{g}} ; \rho_{\mathrm{s}}$ is the density of the particles, $\mathrm{kg} / \mathrm{m}^{3} ; \rho$ is the density of the medium, $\mathrm{kg} / \mathrm{m}^{3} ; g$ is the acceleration of gravity, $\mathrm{m} / \mathrm{s}^{2} ; d$ is the diameter of the spherical particles, $\mathrm{m} ; \mathrm{v}$ is the relative velocity of the particles, $\mathrm{m} / \mathrm{s} ; t$ is the time, $\mathrm{s}$; and $\psi$ is the coefficient of resistance, determined by Reynolds numbers.

In Eq. (5), it is shown that particles started to settle at the instant $v$ is 0 ; at this point, the acceleration $g_{0}=\frac{\rho_{\mathrm{s}}-\rho}{\rho_{\mathrm{s}}} g$ was the maximum number, called the initial acceleration. The medium resistance increased correspondingly and the acceleration reduced gradually with the moving of particles until the resistance equaled the difference of gravity and floatage, and the acceleration equaled 0 , which is called terminal velocity in free settling and represented by $v_{0}$ :

$v_{0}=\sqrt{\frac{\pi d\left(\rho_{\mathrm{s}}-\rho\right) g}{6 \psi \rho}}$ 
According to this definition, the following equation was deduced on a pair of equal settling particles:

$\frac{d_{1} \psi_{2}}{d_{2} \psi_{1}}=\frac{\rho_{s 2}-\rho}{\rho_{s 1}-\rho}$

On the assumption that a spherical particle settled freely in medium, its velocity accelerated from 0 to $v_{\mathrm{I}}$, to $v_{\text {II }}$ and to $v_{t}$ as time $t$ passed by. They were defined as that $0-v_{\mathrm{I}}$ is laminar region, $v_{\mathrm{I}}-v_{\mathrm{II}}$ is transition region and $v_{\mathrm{II}}-v_{t}$ is turbulence. Equation (5) was transformed and subsection integral was used to study the relation between $t$ and $v_{t}$ :

$$
\begin{gathered}
\int_{0}^{t} \mathrm{~d} t=\int_{0}^{v_{\mathrm{I}}} \frac{\pi d \rho_{\mathrm{s}}}{\pi d\left(\rho_{\mathrm{s}}-\rho\right) g-6 \psi \rho v^{2}} d v \\
+\int_{v_{\mathrm{I}}}^{v_{\mathrm{II}}} \frac{\pi d \rho_{\mathrm{s}}}{\pi d\left(\rho_{\mathrm{s}}-\rho\right) g-6 \psi \rho v^{2}} d v \\
+\int_{v_{\mathrm{II}}}^{v_{t}} \frac{\pi d \rho_{\mathrm{s}}}{\pi d\left(\rho_{\mathrm{s}}-\rho\right) g-6 \psi \rho v^{2}} d v
\end{gathered}
$$

Times that the particles spent on the velocity acceleration from 0 to $v_{\mathrm{I}}, v_{\mathrm{I}}$ to $v_{\mathrm{II}}$, and $v_{\mathrm{II}}$ to $v_{t}$ were, respectively, $t_{\mathrm{I}}, t_{\mathrm{II}}$ and $t_{\mathrm{III}}$. The coefficient $\psi$ of the three periods were, respectively, $3 \pi / \operatorname{Re}, 5 \pi / 4 \sqrt{\operatorname{Re}}$ and $\pi / 18$. Particle motion law during the time of $t_{\mathrm{III}}$ period was analyzed mainly, and the integral was used to the last equation.

$$
\begin{aligned}
t_{\mathrm{III}}= & \frac{\pi d \rho_{\mathrm{s}}}{\sqrt{24 \pi d g \psi \rho\left(\rho_{\mathrm{s}}-\rho\right)}} \\
& \times \ln \left\{\frac{\left[\sqrt{\frac{\pi d g\left(\rho_{\mathrm{s}}-\rho\right)}{6 \psi \rho}}+v_{t}\right]\left[\sqrt{\frac{\pi d g\left(\rho_{\mathrm{s}}-\rho\right)}{6 \psi \rho}}-v_{\mathrm{II}}\right]}{\left[\sqrt{\frac{\pi d g\left(\rho_{\mathrm{s}}-\rho\right)}{6 \psi \rho}}-v_{t}\right]\left[\sqrt{\frac{\pi d g\left(\rho_{\mathrm{s}}-\rho\right)}{6 \psi \rho}}+v_{\mathrm{II}}\right]}\right\} \\
t_{\mathrm{III}}= & \frac{\pi d \rho_{\mathrm{s}}}{\sqrt{24 \pi d g \psi \rho\left(\rho_{\mathrm{s}}-\rho\right)}} \ln \left[\frac{\left(v_{0}+v_{t}\right)\left(v_{0}-v_{\mathrm{II}}\right)}{\left(v_{0}-v_{t}\right)\left(v_{0}+v_{\mathrm{II}}\right)}\right]
\end{aligned}
$$

Equation (9) expresses the relation between time and sedimentation velocity of spherical particles in the turbulent region. It was shown that time consumption in reaching the terminal velocity is infinite, and $v_{t}$ can only approach $v_{0}$ infinitely.

The motion difference of two equal settling particles in turbulent region was analyzed according to Eq. (9). A particle's diameter is $d_{1}$ and the other's is $d_{2}$. The two particles settled freely in the medium with density $\rho$. When $d_{1}$ was greater than $d_{2}$, density $\rho_{\mathrm{s} 2}$ was greater than $\rho_{\mathrm{s} 1}$, and $\rho_{\mathrm{s} 1}$ was greater than $\rho$ for the same $v_{0}$ of the two particles. Let the time that particle 1 spent on the velocity acceleration from $v_{\mathrm{II}}$ to $v_{t}$ is $t_{\mathrm{III} 1}$, and time that particle 2 spent on the velocity acceleration from $v_{\text {II }}$ to $v_{t}$ is $t_{\mathrm{III} 2}$. The rate of $t_{\mathrm{III} 2}$ and $t_{\mathrm{III} 1}$ was calculated from the Eq. (9):

$$
\begin{aligned}
\frac{t_{\mathrm{III} 2}}{t_{\mathrm{III} 1}}= & \frac{\pi d_{2} \rho_{s 2}}{\sqrt{24 \pi d_{2} g \psi_{2} \rho\left(\rho_{s 2}-\rho\right)}} \ln \left[\frac{\left(v_{0}+v_{t}\right)\left(v_{0}-v_{\mathrm{II}}\right)}{\left(v_{0}-v_{t}\right)\left(v_{0}+v_{\mathrm{II}}\right)}\right] \\
& / \frac{\pi d_{1} \rho_{s 1}}{\sqrt{24 \pi d_{1} g \psi_{1} \rho\left(\rho_{s 1}-\rho\right)}} \ln \left[\frac{\left(v_{0}+v_{t}\right)\left(v_{0}-v_{\mathrm{II}}\right)}{\left(v_{0}-v_{t}\right)\left(v_{0}+v_{\mathrm{II}}\right)}\right]
\end{aligned}
$$

The last equation was processed and the result was substituted in Eq. (7):

$\frac{t_{\mathrm{III} 2}}{t_{\mathrm{III} 1}}=\frac{\psi_{1} d_{2} \rho_{\mathrm{s} 2}}{\psi_{2} d_{1} \rho_{\mathrm{s} 1}}$

As $\psi_{1}=\psi_{2}=$ a constant, the formula of rate of $t_{\mathrm{III} 2}$ and $t_{\text {III1 }}$ was obtained:

$\frac{t_{\mathrm{III} 2}}{t_{\mathrm{III} 1}}=\left(\frac{d_{2}}{d_{1}}\right)\left(\frac{\rho_{\mathrm{s} 2}}{\rho_{\mathrm{s} 1}}\right)$

In order that motion difference of the equal settling particles in free settling was revealed clearly and further, Eq. (10) was transformed by making use of Eq. (7):

$\frac{t_{\mathrm{III} 2}}{t_{\mathrm{III} 1}}=\frac{\rho_{s 2}\left(\rho_{s 1}-\rho\right)}{\rho_{s 1}\left(\rho_{s 2}-\rho\right)}$

$\frac{t_{\mathrm{III} 2}}{t_{\mathrm{III} 1}}=1-\frac{\rho\left(\rho_{\mathrm{s} 2}-\rho_{\mathrm{s} 1}\right)}{\rho_{s 1}\left(\rho_{\mathrm{s} 2}-\rho\right)}$

Equations (12) and (13) can be summarized as follows: in turbulent region, when two equal settling spherical particles are in the process of settling, the rate of times that the two particles spend on the velocity acceleration from one equal terminal velocity to another one is constant and is related to the density of the medium. When density $\rho_{\mathrm{s} 2}$ was greater than $\rho_{\mathrm{s} 1}$ and $\rho_{\mathrm{s} 1}$ was greater than $\rho$, the constant value was between 0 and 1 . According to Eq. (13), $t_{\mathrm{III} 2}$ was less than $t_{\mathrm{III} 1}$, because density $\rho_{\mathrm{s} 2}$ was greater than $\rho_{\mathrm{s} 1}$ and $\rho_{\mathrm{s} 1}$ was greater than $\rho$. That is to say, when equal settling particles at the same speed settled in a turbulent region, the particle with higher density always reached earlier. It illustrated that the two particles had different movement behavior and displacement in the settling process. The separation of the equal settling particles was based on the different movement and the distance. Obviously, the less the rate of times of the equal settling particles, the greater was the distance of the particles in the same amount of time and the easier the separation of particles.

Considering Eq. (9), let $\frac{\pi d \rho_{\mathrm{s}}}{\sqrt{24 \pi d g \psi \rho\left(\rho_{\mathrm{s}}-\rho\right)}}=A$, then the equation is transformed as:

$$
\begin{aligned}
& t_{\mathrm{III}}=\frac{\pi d \rho_{\mathrm{s}}}{\sqrt{24 \pi d g \psi \rho\left(\rho_{s}-\rho\right)}} \ln \left[\frac{\left(v_{0}+v_{t}\right)\left(v_{0}-v_{\mathrm{II}}\right)}{\left(v_{0}-v_{t}\right)\left(v_{0}+v_{\mathrm{II}}\right)}\right] \\
& v_{t}=\frac{\mathrm{e}^{\frac{t}{A}}-\frac{v_{0}-v_{\mathrm{II}}}{v_{0}+v_{\mathrm{II}}}}{\mathrm{e}^{\frac{t}{A}}+\frac{v_{0}-v_{\mathrm{II}}}{v_{0}+v_{\mathrm{II}}}} v_{0}
\end{aligned}
$$


$\frac{\mathrm{d} s}{\mathrm{~d} t}=\frac{\mathrm{e}^{\frac{t}{A}}-\frac{v_{0}-v_{\mathrm{II}}}{v_{0}+v_{\mathrm{II}}}}{\mathrm{e}^{\frac{t}{A}}+\frac{v_{0}-v_{\mathrm{II}}}{v_{0}+v_{\mathrm{II}}}} v_{0}$

The last equation was deduced by integral and processing:

$s=v_{0} t-2 v_{0} A \ln \frac{\mathrm{e}^{\frac{t}{A}}}{\mathrm{e}^{\frac{t}{A}}+\frac{v_{0}-v_{\mathrm{II}}}{v_{0}+v_{\mathrm{II}}}}+2 v_{0} A \ln \frac{v_{0}+v_{\mathrm{II}}}{2 v_{0}}$

When the starting velocity was $v_{\text {II }}$, the formula for different settling distances of the equal settling particles in the turbulent region was derived from Eq. (14):

$$
\begin{aligned}
\Delta s= & s_{2}-s_{1} \\
= & v_{0}\left(t_{2}-t_{1}\right) \\
& -2 v_{0}\left(A_{2} \ln \frac{\mathrm{e} \frac{t_{2}}{A_{2}}}{e \frac{t_{2}}{A_{2}}+\frac{v_{0}-v_{\mathrm{II}}}{v_{0}+v_{\mathrm{II}}}}-A_{1} \ln \frac{\mathrm{e} \frac{t_{1}}{A_{1}}}{\mathrm{e} \frac{t_{1}}{A_{1}}+\frac{v_{0}-v_{\mathrm{II}}}{v_{0}+v_{\mathrm{II}}}}\right) \\
& +2 v_{0}\left(A_{2}-A_{1}\right) \ln \frac{v_{0}+v_{\mathrm{II}}}{2 v_{0}}
\end{aligned}
$$

When $t_{1}=t_{2}$ and both approached positive infinity, the last equation was transformed into Eq. (15):

$\Delta s=2 v_{0}\left(A_{2}-A_{1}\right) \ln \frac{v_{0}+v_{\mathrm{II}}}{2 v_{0}}$

The values of $A, \psi$, and Eqs. (6) and (7) were substituted into Eq. (15). The formula of the different of extreme settling distances of the equal settling particles in turbulent region is shown as:

$\Delta s=3\left(d_{2}-d_{1}\right) \ln \frac{v_{0}+v_{\mathrm{II}}}{2 v_{0}}$

According to Eq. (16), there was motion difference of the equal settling particles based on their different nature in free settling.

The diameters of a pair of equal settling particles were $d_{1}, d_{2}$, respectively. Their terminal velocities both were $v_{0}$, and the flow velocity of upward fluid field was $v_{0}$ as well. The upward velocity of fluid field was equal to the terminal velocity and the particles were resting. Meanwhile, the upward velocity increased to $v_{0}+\Delta v$.

The velocities of the two particles were 0 in the initial state of the fluid field and the particles had maximum acceleration,

$\frac{\mathrm{d} v}{\mathrm{~d} t}=\frac{6 \psi\left(v_{0}+\Delta v\right)^{2} \rho}{\pi d \rho_{\mathrm{s}}}-\frac{\rho_{\mathrm{s}}-\rho}{\rho_{\mathrm{s}}} g$

The medium resistance increased with the increase of the particles' velocity. When there was a balance between resistance, gravity and floatage, the particles reached the terminal velocity $\Delta v$ and there was maximum difference between the two equal settling particles.

$\frac{t_{2}}{t_{1}}=\frac{\rho_{\mathrm{s} 2}\left(\rho_{\mathrm{s} 1}-\rho\right)}{\rho_{\mathrm{s} 1}\left(\rho_{\mathrm{s} 2}-\rho\right)}$ $\frac{t_{2}}{t_{1}}=1-\frac{\rho\left(\rho_{\mathrm{s} 2}-\rho_{\mathrm{s} 1}\right)}{\rho_{\mathrm{s} 1}\left(\rho_{\mathrm{s} 2}-\rho\right)}$

The particle with lower density always reached the velocity $v_{\mathrm{s}}$. It illustrated that the particles with higher density was behind the particle with lower density in the process of movement. By designing an appropriate device and technology based on the theory of different motion, equal settling particles can be separated effectively.

The separation mechanism of a TDSB

The expanding tubular structure of the separation bed causes a gradually decreasing water velocity as its flow proceeds along the axis. The force of gravity creates a corresponding change to the distribution of the flow velocity given a certain angle. Thus, a special fluid field forms where velocity variations exist at different positions along the tube.

When the material passes through the tube along with the water, the differences in particle density, granularity and shape create different trajectories for different particles: lower density material discharges along with the water flow, but higher density materials are kept in the bottom of the bed and discharge through the material chute. The distributor plays the roles of redistributing material and establishing hydraulic conditions: Water flow is constricted to certain regions while passing through the device because of the aperture. Gradually increasing drag forces causes some particles that do not match the hydraulic conditions to cross the distributor only with difficulty. The even redistribution of the hydraulic conditions causes the same velocity within every aperture. This avoids the development of unfavorable hydraulic conditions, including short circuit, back flow, and boundary layer velocity.

Particles with different terminal velocities are separated in the flow field of the TDSB. Particle density, size, and shape affect the terminal velocity. Figure 3 shows how velocity and direction of a particle depends on the settling velocity of the particles and the water velocity. Trajectory "a" shows how a greater settling velocity causes a shorter path length, and a shorter settling time, compared to trajectory " $b$ ". When the particle travel distance is larger than the boundary length of the separator, particles flow out of the apparatus with the water as shown by trajectory "c". Particles separate during the circulation by settlement, gliding, raising, and drifting to different positions. The lighter particles are extracted from the top of the separation bed with water, and the heavier particles are discharged from the bottom of the separation bed. 


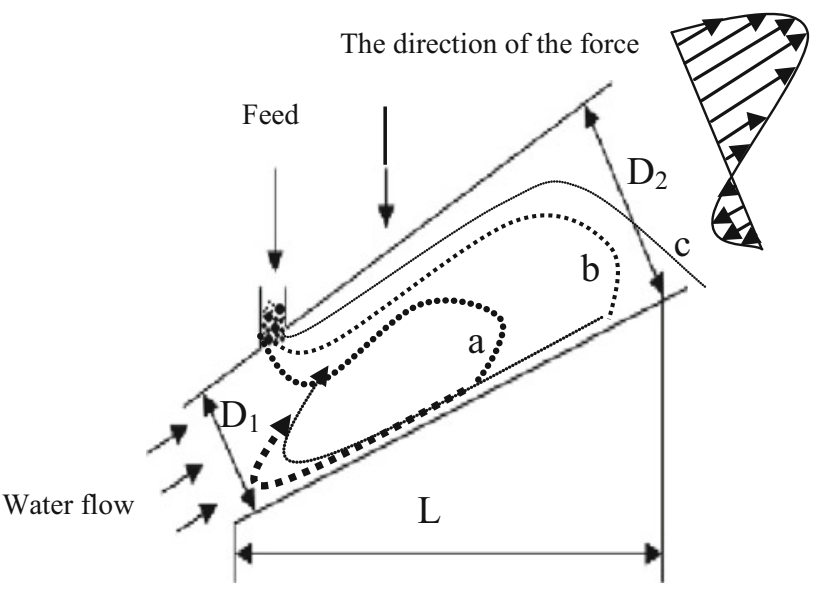

Fig. 3 Movement trajectories of different particles

\section{Results and discussion}

The main factors influencing the effective separation of waste PCB are water discharge rate, tube obliquity, and feed rate of the material. An experimental scheme was designed using the Taguchi OA module of "DesignExpert." The water discharge was set at 3.5, 4.5, and $5.5 \mathrm{~m}^{3} / \mathrm{h}$; the material feed rate as 200,250 , and $300 \mathrm{~g} / \mathrm{min}$; the obliquity was $30^{\circ}, 35^{\circ}$, and $40^{\circ}$. The experimental data are shown in Table 1.
The amount of waste PCB material smaller than $0.074 \mathrm{~mm}$ is very low and the metal content of this portion is less. Therefore, an orthogonal experiment, a $3^{2}\left(L^{4}\right)$, was designed to separate and recover waste PCB of a size range $-0.074 \mathrm{~mm}$. The experimental results from these trials are shown in Table 2. The metal recovery is $93.42 \%$ and the separation efficiency is $77.63 \%$ when the water discharge is $2 \mathrm{~m}^{3} / \mathrm{h}$, the obliquity is $35^{\circ}$, and the material feed rate is $450 \mathrm{~g} / \mathrm{min}$. The superfine products in a size range of $-0.074 \mathrm{~mm}$ can be recovered effectively under suitable operating condition using the tapered diameter separation bed.

The metal content after separating the larger sized concentrate ranges from 74.09 to $94.12 \%$. The metal recovery ranges from 93.68 to $97.36 \%$, and the separation efficiency ranges from 84.93 to $93.92 \%$. Metal from the waste PCB is concentrated effectively. This method provides high purity metal product for further separation and purification. Comprehensive recovery efficiency was taken as the main criterion for evaluation and an analysis was conducted using the Taguchi OA module of Design-Expert. The analysis of variance for every model and a comprehensive analysis of the correlation coefficient are shown in Tables 3 and 4 . The results indicate that a linear model is the recommended type. Quadratic or cubic models are aliased and the model, in units of the actual factors, for the comprehensive recovery efficiency (CRE) is

Table 1 Experimental data: separating waste PCB material, sized 1 to $0.074 \mathrm{~mm}$

\begin{tabular}{|c|c|c|c|c|c|c|c|c|}
\hline No. & $\begin{array}{l}\text { Water discharge } \\
\text { rate }\left(\mathrm{m}^{3} / \mathrm{h}\right)\end{array}$ & $\begin{array}{l}\text { Material feed } \\
\text { rate }(\mathrm{g} / \mathrm{min})\end{array}$ & $\begin{array}{l}\text { Obliquity } \\
\left({ }^{\circ}\right)\end{array}$ & Product & $\begin{array}{l}\text { Yield } \\
(\%)\end{array}$ & $\begin{array}{l}\text { Content } \\
(\%)\end{array}$ & $\begin{array}{l}\text { Recovery } \\
(\%)\end{array}$ & $\begin{array}{l}\text { Efficiency } \\
(\%)\end{array}$ \\
\hline \multirow[t]{2}{*}{1} & \multirow[t]{2}{*}{3.5} & \multirow[t]{2}{*}{200} & \multirow[t]{2}{*}{35} & Metal concentrate & 31.62 & 78.98 & \multirow[t]{2}{*}{96.33} & \multirow[t]{2}{*}{87.22} \\
\hline & & & & Non-metallic products & 68.38 & 1.39 & & \\
\hline \multirow[t]{2}{*}{2} & \multirow[t]{2}{*}{3.5} & \multirow[t]{2}{*}{300} & \multirow[t]{2}{*}{40} & Metal concentrate & 27.25 & 83.47 & \multirow[t]{2}{*}{96.10} & \multirow[t]{2}{*}{89.56} \\
\hline & & & & Non-metallic products & 72.75 & 1.27 & & \\
\hline \multirow[t]{2}{*}{3} & \multirow[t]{2}{*}{3.5} & \multirow[t]{2}{*}{250} & \multirow[t]{2}{*}{30} & Metal concentrate & 30.97 & 74.09 & \multirow[t]{2}{*}{97.36} & \multirow[t]{2}{*}{84.93} \\
\hline & & & & Non-metallic products & 69.03 & 0.90 & & \\
\hline \multirow[t]{2}{*}{4} & \multirow[t]{2}{*}{4.5} & \multirow[t]{2}{*}{200} & \multirow[t]{2}{*}{40} & Metal concentrate & 26.90 & 82.49 & \multirow[t]{2}{*}{93.68} & \multirow[t]{2}{*}{87.91} \\
\hline & & & & Non-metallic products & 73.10 & 2.05 & & \\
\hline \multirow[t]{2}{*}{5} & \multirow[t]{2}{*}{4.5} & \multirow[t]{2}{*}{300} & \multirow[t]{2}{*}{30} & Metal concentrate & 25.85 & 87.91 & \multirow[t]{2}{*}{95.79} & \multirow[t]{2}{*}{91.77} \\
\hline & & & & Non-metallic products & 74.15 & 1.35 & & \\
\hline \multirow[t]{2}{*}{6} & \multirow[t]{2}{*}{4.5} & \multirow[t]{2}{*}{250} & \multirow[t]{2}{*}{35} & Metal concentrate & 26.36 & 86.45 & \multirow[t]{2}{*}{96.13} & 91.16 \\
\hline & & & & Non-metallic products & 73.64 & 1.25 & & \\
\hline 7 & 5.5 & 200 & 30 & Metal concentrate & 24.69 & 90.73 & 94.08 & 92.39 \\
\hline & & & & Non-metallic products & 75.31 & 1.87 & & \\
\hline 8 & 5.5 & 250 & 35 & Metal concentrate & 24.26 & 94.12 & 93.73 & 93.92 \\
\hline & & & & Non-metallic products & 75.74 & 2.02 & & \\
\hline 9 & 5.5 & 300 & 40 & Metal concentrate & 25.08 & 90.06 & 94.14 & 92.08 \\
\hline & & & & Non-metallic products & 74.92 & 1.88 & & \\
\hline
\end{tabular}


Table 2 Experimental data: separating waste PCB sized $-0.074 \mathrm{~mm}$

\begin{tabular}{|c|c|c|c|c|c|c|c|c|}
\hline No. & $\begin{array}{l}\text { Water discharge } \\
\text { rate }\left(\mathrm{m}^{3} / \mathrm{h}\right)\end{array}$ & $\begin{array}{l}\text { Material feed } \\
\text { rate }(\mathrm{g} / \mathrm{min})\end{array}$ & $\begin{array}{l}\text { Obliquity } \\
\left({ }^{\circ}\right)\end{array}$ & Product & $\begin{array}{l}\text { Yield } \\
(\%)\end{array}$ & $\begin{array}{l}\text { Content } \\
(\%)\end{array}$ & $\begin{array}{l}\text { Recovery } \\
(\%)\end{array}$ & $\begin{array}{l}\text { Efficiency } \\
(\%)\end{array}$ \\
\hline \multirow[t]{2}{*}{1} & \multirow[t]{2}{*}{2} & \multirow[t]{2}{*}{300} & \multirow[t]{2}{*}{30} & Metal concentrate & 1.92 & 54.86 & \multirow[t]{2}{*}{89.68} & \multirow[t]{2}{*}{70.14} \\
\hline & & & & Non-metallic products & 98.08 & 0.12 & & \\
\hline \multirow[t]{2}{*}{2} & \multirow[t]{2}{*}{2} & \multirow[t]{2}{*}{450} & \multirow[t]{2}{*}{35} & Metal concentrate & 1.72 & 64.51 & \multirow[t]{2}{*}{93.42} & \multirow[t]{2}{*}{77.63} \\
\hline & & & & Non-metallic products & 98.28 & 0.08 & & \\
\hline \multirow[t]{2}{*}{3} & \multirow[t]{2}{*}{2.5} & \multirow[t]{2}{*}{300} & \multirow[t]{2}{*}{35} & Metal concentrate & 2.27 & 60.41 & \multirow[t]{2}{*}{67.51} & \multirow[t]{2}{*}{63.86} \\
\hline & & & & Non-metallic products & 97.73 & 0.68 & & \\
\hline 4 & 2.5 & 450 & 30 & Metal concentrate & 1.29 & 76.13 & 48.23 & 60.59 \\
\hline
\end{tabular}

Table 3 Analysis of variance for different models

Table 4 Comprehensive analysis of $R^{2}$

Table 5 Analysis of variance

Table 6 Comprehensive table for recommended model

\begin{tabular}{lclllll}
\hline $\begin{array}{l}\text { Variance } \\
\text { source }\end{array}$ & $\begin{array}{l}\text { Sum of } \\
\text { squares }\end{array}$ & $\begin{array}{l}\text { Degrees of } \\
\text { freedom }\end{array}$ & $\begin{array}{l}\text { Mean } \\
\text { square }\end{array}$ & $F$ value & Prob $>F$ & \\
\hline Mean & $73,125.44$ & 1 & $73,125.44$ & & & Suggested \\
Linear & 54.45 & 3 & 18.15 & 6.21 & 0.0386 & \\
2FI & 11.87 & 3 & 3.96 & 2.89 & 0.2676 & Aliased \\
Quadratic & 2.74 & 2 & 1.37 & & & Aliased \\
Cubic & 0 & 0 & & & & \\
Residual & 0 & 0 & & & & \\
Total & $73,194.49$ & 9 & $8,132.72$ & & & \\
\hline
\end{tabular}

\begin{tabular}{lllllll}
\hline Model & $\begin{array}{l}\text { Standard } \\
\text { variance }\end{array}$ & $R^{2}$ & $\begin{array}{l}R^{2} \text { correction } \\
\text { value }\end{array}$ & $\begin{array}{l}R^{2} \text { predicted } \\
\text { value }\end{array}$ & PRESS & \\
\hline Linear & 1.71 & 0.79 & 0.66 & 0.21 & 54.48 & Suggested \\
2FI & 1.17 & 0.96 & 0.84 & -0.70 & 117.44 & \\
Quadratic & & & & & + & Aliased \\
Cubic & & & & & + & Aliased \\
\hline
\end{tabular}

\begin{tabular}{lcccccc}
\hline $\begin{array}{l}\text { Variance } \\
\text { sources }\end{array}$ & $\begin{array}{l}\text { Sum of } \\
\text { squares }\end{array}$ & $d f$ & $\begin{array}{l}\text { Mean } \\
\text { square }\end{array}$ & $F$ value & Prob $>$ F & \\
\hline Model & 54.45 & 3 & 18.15 & 6.21 & 0.0386 & Significant \\
$A$ & 48.05 & 1 & 48.05 & 16.45 & 0.0098 & \\
$B$ & 6.30 & 1 & 6.30 & 2.16 & 0.2018 & \\
$C$ & 0.01 & 1 & 0.01 & 0.0041 & 0.9512 & \\
Residual & 14.60 & 5 & 2.92 & & & \\
Cor total & 69.05 & 8 & & & & \\
\hline
\end{tabular}

\begin{tabular}{lrlr}
\hline Standard variance & 1.71 & $R^{2}$ & 0.79 \\
\hline Mean value & 90.14 & Adjusted $R^{2}$ & 0.66 \\
C.V. $(\%)$ & 1.90 & Predicted $R^{2}$ & 0.21 \\
PRESS & 54.48 & Adequate precision & 6.75 \\
\hline
\end{tabular}


Table 7 Expected values of the factors

\begin{tabular}{lcccccc}
\hline Factor & $\begin{array}{l}\text { Coefficient } \\
\text { estimate }\end{array}$ & $d f$ & $\begin{array}{l}\text { Standard } \\
\text { error }\end{array}$ & $\begin{array}{l}\text { 95 \% } \\
\text { CI Low }\end{array}$ & $\begin{array}{l}\text { 95 \% } \\
\text { CI High }\end{array}$ & VIF \\
\hline Intercept & 90.14 & 1 & 0.57 & 88.67 & 91.60 & \\
Discharge of water $(A)$ & 2.83 & 1 & 0.70 & 1.04 & 4.62 & 1 \\
Feed rate of the material $(B)$ & 1.04 & 1 & 0.71 & -0.78 & 2.86 & 1.03 \\
Obliquity $(C)$ & -0.05 & 1 & 0.71 & -1.86 & 1.77 & 1.03 \\
\hline
\end{tabular}

Table 8 Comprehensive analysis of separation results

\begin{tabular}{lllllllr}
\hline $\begin{array}{l}\text { No. } \\
\text { value }\end{array}$ & $\begin{array}{l}\text { Actual } \\
\text { value }\end{array}$ & Residual & Leverage & $\begin{array}{l}\text { Student } \\
\text { residual }\end{array}$ & $\begin{array}{l}\text { Cook's } \\
\text { distance }\end{array}$ & Outlier \\
\hline 1 & 87.22 & 86.27 & 0.95 & 0.45 & 0.75 & 0.12 & 0.65 \\
2 & 89.56 & 88.30 & 1.26 & 0.56 & 1.12 & 0.40 & 1.31 \\
3 & 84.93 & 87.35 & -2.42 & 0.45 & -1.91 & 0.74 & -2.97 \\
4 & 87.91 & 89.05 & -1.15 & 0.51 & -0.96 & 0.24 & -0.97 \\
5 & 91.77 & 91.22 & 0.54 & 0.51 & 0.45 & 0.05 & 0.42 \\
6 & 91.16 & 90.14 & 1.02 & 0.11 & 0.63 & 0.01 & 0.21 \\
7 & 92.39 & 91.98 & 0.41 & 0.56 & 0.37 & 0.04 & 0.38 \\
8 & 93.92 & 92.97 & 0.96 & 0.28 & 0.66 & 0.04 & 0.38 \\
9 & 92.38 & 93.96 & -1.58 & 0.56 & -1.40 & 0.63 & -1.82 \\
\hline
\end{tabular}

$\mathrm{CRE}=72.53+2.83 \times A+0.02 \times B-0.0091 \times C$

where $A$ is the water discharge rate in $\mathrm{m}^{3} / \mathrm{h} ; B$ is the feed rate of the material in $\mathrm{g} / \mathrm{min}$; and $C$ is the obliquity in degrees.

An analysis of variance for the trials as in Table 5 shows that the linear model is significant. The standard variance of the recommended model is 1.71 and the adequate precision of the recommended model is 6.75. The comprehensive table of the recommended model is shown in Table 6. Diagnostic statistics for the trials are shown in Tables 7 and 8, which show that the confidence interval (CI) is [88.67-91.60], and that the predicted value is close to the actual value. All assessment indicators of residual, leverage, student residual, Cook's distance and outlier meet the required standard.

\section{Conclusion}

1. A laboratory-scale tapered diameter separation bed was designed using computational fluid mechanics. Efficient recovery of metal concentrate from waste PCB was the design goal. An upward sloping flow field is better for producing an increasing velocity gradient. Consequently, the lower limits of separation are widened. Experimental research indicates that the lower separation limit of the TDSB can be close to zero.
2. Turbulence and laminar flow coexist in one tube due to the tapered diameter. Turbulence increases the mixing of material with water, which is beneficial for separation of different material particles. Laminar flow provides a favorable settling environment propitious for effective separation of metal and non-metallic particles by kinetic properties.

3. Experimental separation of waste PCB materials having the size range $1-0.074 \mathrm{~mm}$ indicated that, under different experimental conditions, the metal content of the concentrate ranged from 74.09 to $94.12 \%$. Metal recovery ranged from 93.68 to $97.36 \%$ and separation efficiency ranged from 84.93 to $93.92 \%$ during these trials. The metal from the waste PCB is effectively concentrated.

4. A linear model giving comprehensive efficiency from the experimental parameters for material in the size range $-1+0.074 \mathrm{~mm}$ was established using the Taguchi OA model of Design-Expert. The model of comprehensive recovery efficiency is: $\mathrm{CRE}=72.53+$ $2.83 \times A+0.02 \times B-0.0091 \times C$. The standard variance is 1.71 and the accuracy is 6.75 . The confidence interval is [88.67, 91.60]. The predicted value of the model is very close to the observed value. The student residual, Cook's distance and outliers are all close to zero. The influence of the linear model on the comprehensive model is distinct. The analytical results indicate that the linear model is effective. 
5. Superfine products having a size $-0.074 \mathrm{~mm}$ were recovered effectively under suitable operating conditions of the tapered diameter separation bed. Metal recovery was $93.42 \%$ and the separation efficiency was $77.63 \%$ when the rate of water discharge was $2 \mathrm{~m}^{3} / \mathrm{h}$, the obliquity was $35^{\circ}$, and the feed rate of the material was $450 \mathrm{~g} / \mathrm{min}$. A new technique was brought forward for recycling metals from waste $\mathrm{PCB}$, which offers an approach to resource recycling and the prevention of environmental pollution.

Acknowledgments The authors acknowledge the support by the National Natural Science Foundation of China for Innovative Research Group (No. 50921002), Fundamental Research Funds for the Central Universities (No. 2012QNA12).

\section{References}

Chien MK, Shih LH (2007) An empirical study of the implementation of green supply chain management practices in the electrical and electronic industry and their relation to organizational performances. Int J Environ Sci Technol 4(3):383394

Cui J, Forssberg E (2003) Mechanical recycling of waste electric and electronic equipment: a review. J Hazard Mater 99(3):243263

Cui J, Zhang L (2008) Metallurgical recovery of metals from electronic waste: a review. J Hazard Mater 158(2-3):228256

Das A, Vidyadhar A, Mehrotra SP (2009) A novel flowsheet for the recovery of metal values from waste printed circuit boards. Resour Conserv Recycl 53(8):464-469

Duan CL, Wen XF, Shi CS, Zhao YM, Wen BF, He YQ (2009) Recovery of metals from waste printed circuit boards by a mechanical method using a water medium. J Hazard Mater 166(1):478-482

Guan J, Li Y, Lu M (2008) Product characterization of waste printed circuit board by pyrolysis. J Anal Appl Pyrolysis 83(2): $185-189$

Guo JY, Guo J, Xu Z (2009) Recycling of non-metallic fractions from waste printed circuit boards: a review. J Hazard Mater 168(2-3): $567-590$

He YQ, Zhao YM (2009) Technology of pulsing air separation. Chemical Engineering Industry Press, Beijing

He W, Li G, Ma X, Wang H, Huang J, Xu M, Huang C (2006) WEEE recovery strategies and the WEEE treatment status in China. J Hazard Mater 136(3):502-512 11 pages

He Y, Duan C, Wang H, Zhao Y, Tao D (2011) Separation of metal laden waste using pulsating air dry material separator. Int $\mathrm{J}$ Environ Sci Technol 8(1):73-82

Huang K, Guo J, Xu Z (2009) Recycling of waste printed circuit boards: a review of current technologies and treatment status in China. J Hazard Mater 164(2-3):399-408

Kara SS (2011) Evaluation of outsourcing companies of waste electrical and electronic equipment recycling. Int J Environ Sci Technol 8(2):291-304
Kim E, Kim M, Lee J, Jeong J, Pandey BD (2011) Leaching kinetics of copper from waste printed circuit boards by electrogenerated chlorine in $\mathrm{HCl}$ solution. Hydrometallurgy 107(3-4): 124-132

Lee JC, Song HT, Yoo JM (2007) Present status of the recycling of waste electrical and electronic equipment in Korea. Resour Conserv Recycl 50(4):380

Li J, Lu H, Guo J, Xu Z, Zhou Y (2007a) Recycle technology for recovering resources and products from waste printed circuit boards. Environ Sci Technol 41(6):1995-2000

Li J, Xu Z, Zhou Y (2007b) Application of corona discharge and electrostatic force to separate metals and nonmetals from crushed particles of waste. J Electrostat 65(4):233238

Li J, Lu H, Liu SS, Xu Z (2008) Optimizing the operating parameters of corona electrostatic separation for recycling waste scraped PCB by computer simulation of electric field. J Hazard Mater 153(1-2):269-275

Li J, Duan H, Yu K, Liu L, Wang S (2010) Characteristic of low-temperature pyrolysis of printed circuit boards subjected to various atmospheres. Resour Conserv Recycl 54(11):810 815

Long L, Sun S, Zhong S, Dai W, Liu J, Song W (2010) Using vacuum pyrolysis and mechanical processing for recycling waste printed circuit boards. J Hazard Mater 177(1-3):626-632

Lu H, Li J, Guo J, Xu Z (2008) Movement behavior in electrostatic separation: recycling of metal materials from waste printed circuit boards. J Mater Process Technol 197(1-3): $101-108$

Mohiuddin KM, Zakir HM, Otomo K et al (2010) Geochemical distribution of trace metal pollutants in water and sediments of downstream of an urban river. Int J Environ Sci Technol 7(1): $17-28$

Oishi T, Koyama K, Alam S, Tanaka M, Lee JC (2007) Recovery of high purity copper cathode from printed circuit boards using ammoniacal sulfate or chloride solutions. Hydrometallurgy 89(1-2):82-88

Owens CV, Lambright C, Bobseine K, Ryan B, Gray LE, Gullett BK, Wilson VS (2007) Identification of estrogenic compounds emitted from the combustion of computer printed circuit boards in electronic waste. Environ Sci Technol 41(24):85068511

Park YJ, Fray DJ (2009) Recovery of high purity precious metals from printed circuit boards. J Hazard Mater 164(2-3):11521158

Tippayawong N, Khongkrapan P (2009) Development of a laboratory scale air plasma torch and its application to electronic waste treatment. Int J Environ Sci Technol 6(3):407-414

Veit HM, Bernardes AM, Ferreira JZ, Tenorio JAS, Malfatti CF (2006) Recovery of copper from printed circuit boards scraps by mechanical processing and electrometallurgy. J Hazard Mater 137(3):1704-1709

Wu J, Li J, Xu ZM (2009) A new two-roll electrostatic separator for recycling of metals and nonmetals from waste printed circuit board. J Hazard Mater 161(1):257-262

Zhao YM, Wen XF, Li BB (2004) Recovery of copper from waste printed circuit board. J Miner Metall Process 21(2): 99-102

Zhao YM, Duan CL, Zhang HJ (2008) Research on metals recycling from waste printed circuit board by mechanical processing of wet crushing and wet separation. In: XXIV international mineral processing congress. Beijing, China L:24-28 
Zhao YM, Duan CL, He YQ (2009) Theory and technology of physical separation of electronic scrap. Science Press, Beijing

Zheng Y, Shen Z, Ma S, Cai C, Zhao X, Xing Y (2009) A novel approach to recycling of glass fibers from nonmetal materials of waste printed circuit boards. J Hazard Mater 170(2-3): 978-982

Zhou Y, Qiu K (2010) A new technology for recycling materials from waste printed circuit boards. J Hazard Mater 175(1-3): $823-828$ 